\title{
The construction of knowledge through visual perceptual training in visual arts
}

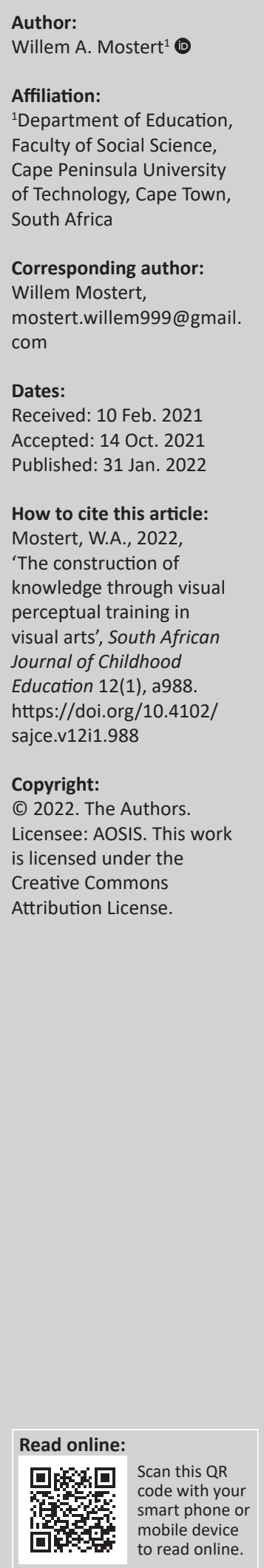

Background: Visual perception and observational skills are an essential part of Visual Arts education, through which young learners, in the primary school, acquire important and necessary skills to create artworks during their creative projects. These skills provide learners in the primary school the opportunity to overcome their self-imposed criticism to their own works of art. Similar research projects highlight the inability of learners in the middle childhood to creatively express what they visually perceive.

Aim: The study sought to assist learners in the middle childhood to overcome the slump in their creative attempts through a series of visual sharpening exercises, in the form of an Art intervention.

Setting: A qualitative case study with elements of action research was conducted at a single site at a primary school in the Northern Suburbs of Cape Town.

Methods: The participants of the study comprised of four grade 5 classes divided into a test group and control group. The intervention was administered to the test group in the form of visual sharpening exercises. The practical projects of four grade 5 classes were assessed, analysed, compared, and the findings were discussed according to the themes identified during the study.

Results: The results indicate factors that might influence the visual perceptual skills of learners in middle childhood, while completing Visual Art projects. Analysis of the research data revealed an increase in the test group's score compared to the control group. There was a marked effect on the test group participants' ability to record what they visually perceived.

Conclusion: This study investigated and highlights shortcomings in the CAPS Visual Art curriculum for Grade 5. Bridging the gap between practice and curriculum shortfalls is important. The study suggests that the Department of Education (DoE) should supplement the Visual Arts curriculum with visual perceptual training for middle childhood learners.

Keywords: visual arts education; visual perception; middle childhood; U-curve; art education.

\section{Introduction}

Visual Art education plays an important and vital role in the holistic development of young children. During the middle childhood phase of their development, children's pursuit of realistic renderings in their art projects increases. Their frustration and hesitation to create is fuelled by their inability to artistically render what they visually perceive. Children in the middle childhood are between the ages of 10 and 11, and their self-imposed criticism of their own work overshadows their willingness to create in 2D. In many cases, these children cease to value creating in art as an expressive outlet and subsequently lose interest in Visual Art. This decline in their artistic interest and creative output is known as the U-curve/creative slump (Wachowiak \& Clements 2010:180).

To assist them during this period in their artistic development, a visual perceptual sharpening intervention project was designed and administered to four Grade 5 classes at a single site. The intervention was conducted during regular school hours and supplemented the Visual Arts curriculum as set out for Grade 5 by the Department of Education (DoE). The aim of the intervention was not to inhibit the creativity of the participants, but to sharpen their visual perceptual and observational skills and to enable them to visually render what they observed during Visual Art lessons.

\section{Conceptual framework of the study}

The conceptual framework of the study was based on the theories of Piaget's (1952) cognitive development and Edward's (1999) cognitive shift theory. Piaget believed that knowledge is actively 
constructed through the interactions of what is experienced. Learning is of a self-constructed nature that augments knowledge. When learners are taught to apply new skills and find meaning in what they experience, new knowledge is being constructed (Ghazi \& Ulah 2015:78). Through visual perception learners are able to understand and analyse their surroundings, thus further developing and enhancing their cognitive growth. Visual Arts can teach learners to recognise visual stimuli and to interpret what they perceive. Through a boundless interaction between the learners and their environment, cognitive growth can result in a better understanding of what is perceived (Cook \& Cook 2005:6).

Edwards (1999) believed that visual and perceptual thinking can enable learners to recognise the differences in what is perceived and their ability to render it in their art. When a cognitive shift is made to visually understanding what is being perceived, it can help develop strategies to manipulate visual information, to construct new knowledge.

\section{Literature review}

The literature reviewed for this study focussed on the declining interest of middle childhood learners to create in 2D and this can be linked to the U-curve model, development of artistic expression and visual perception in art.

Authors such as Edwards (1999), Carrol and Tucker (2007) and Zimmerman (2009) suggested that effects of the U-curve slump in artistic development can be eased by an intervention. The U-curve model, according to Wachowiak and Clements (2010:180), is the decline in learners' creativity that is caused by their 'self-imposed demands to photographic realism'. Learners become self-conscious of their ability to depict objects as they perceive them, which results in learners doubting their ability to produce imaginative and creative works of art. Unfortunately, very few learners regain their self-confidence, and as a result, do not resume their creative attempts (Wachowiak \& Clements 2010:180). The focus of the study was to ascertain whether the enhancement of their visual perceptual skills (Orde 1997:271) will assist young learners in their observational abilities and skills, helping them to overcome this challenging period in their development, leading to an enhancement in their artwork at school. Quality Visual Arts education offers learners the opportunity to learn and develop through a creative approach.

\section{Quality visual arts education}

Expertly taught quality Visual Arts education in the primary school pre-amps several interrelated factors that enhance the holistic development of learners. Quality Visual Arts education aims to develop an array of perceptual skills that assist learners in enhancing and accessing their cognitive resources that are vital during art-making projects (Kiese-Himmel et al. 2015:47).

Anttila et al. (2014:2) argued that integration between sensory input and cognition is of vital importance when learners are taught skills and techniques during art projects. Educators need to reiterate and reinforce the importance of what is taught for learners to understand that art-making is not only a fun activity, but that their perceptual awareness and observation are being refined.

Eisner (2002:26) suggested that when cognition is an active process during the creation of Visual Arts, knowledge is being constructed from different domains of the brain. While learners create art, newly formed concepts and knowledge are linked to existing knowledge, which allows them to creatively and systematically solve problems they may encounter. During this process, meta-cognition takes place.

\section{Visual perception and art education}

Visual perception is tightly related to cognition and when we view an object or scene we have to interpret what we perceive (Cahen \& Tacca 2013:2). The link between cognition and perception is what caused great frustration amongst the participants of this study. Payne (2012:246) cited that cognition forms the basis of our understanding of what we visually perceive and is a result of newly formed understandings of the dimensions of objects and images. During the creation of art projects, learners' visual perceptual abilities play a vital role in how they present and recreate perceived objects and experiences. Teaching learners to perceive and visualise objects they are recreating in their artworks is of utmost importance.

The enhancement of the following skills can assist learners in their art projects:

- Visual problem-solving.

- Intrinsic visual skills.

- Perceptual learning.

- Visual memory.

- Mental imagery.

Quality and meaningful art education can increase and develop spatial awareness, visual thinking, visual problem-solving, and mental imagery formation, as it enhances cognitive orientation and perceptual learning (Haanstra 1996:179).

\section{Art intervention}

The planned intervention was aimed to assist the participants in an understanding of new techniques and to allow them to construct their own knowledge of visual perceptual skills. Pujara, Atkins and McMahon (2014:4) cited that an intervention is a person-centred approach that seeks to change understandings, knowledge, behaviours, and attitudes of practice or individuals. An intervention in art education seeks to improve the practice or abilities of the participants.

When a successful instructional intervention in Visual Arts is implemented, it promotes learner involvement and allows them to explore different techniques and materials. Through their engagement, learners can enhance their creative 
abilities, which in return, improves their drawing and constructive abilities as well as their interpretive skills (Letsiou 2014:14). Machera (2017:733) postulated that learners may benefit from an intervention when it is properly administered. One of the benefits is that it enables learners to self-direct their projects. An intervention in Visual Arts can bring about the following outcomes:

- Learners show enjoyment, pride, and a sense of achievement.

- Learners form important skills, techniques, appreciation, and knowledge

- Learners can develop personally, especially self-esteem and self-confidence.

- Learners develop socially in teamwork and the awareness of other learners.

Visual Arts education intervention is of critical importance for learners to foster creative thinking, imagination, and innovation. Polat (2009:2567) suggested that perceptual learning can be used in a variety of visual tasks and that visual learning is task- and stimulus-specific. The human visual system can adapt according to behavioural demands such as training and practice to improve visual perception. Deveau and Seitz (2014:1) also cited that perceptual learning and training show long-lasting improvements in visual tasks, and the benefits can last for months and even for years.

\section{Research methodology Research design}

A qualitative instrumental case study approach, with an element of action research, was the method of inquiry. Guided by Creswell (2007:73), a case study was used to explore a bounded system of a classroom for two school terms to collect detailed and in-depth data. A case study views the phenomenon in its real-life context, necessitating different types of data to be collected (Cohan, Manion \& Morrison 2007:254). Bassey (1999:24) stated that the importance of a case study in an educational setting is that the researcher can observe the characteristics of the case while forming an in-depth understanding of the phenomenon under investigation. The research set out to answer the following main research question:

TABLE 1: Data collection tools and procedures.

\begin{tabular}{|c|c|}
\hline Instrument & Purpose \\
\hline Pre-test & $\begin{array}{l}\text { 1. The starting point of the study to determine that the } \\
\text { participants' observational skills and abilities were on } \\
\text { par with their developmental stage of artistic expression, } \\
\text { as described by Lowenfeld and Brittain (1975). } \\
\text { 2. The pre-test was compared with the post-test to } \\
\text { determine the effectiveness of the intervention lessons. }\end{array}$ \\
\hline $\begin{array}{l}\text { Observational field } \\
\text { notes }\end{array}$ & $\begin{array}{l}\text { 1. To capture the 'voice' of the participants' experience } \\
\text { during the study. } \\
\text { 2. To supplement the visual data collected. }\end{array}$ \\
\hline Intervention lessons & $\begin{array}{l}\text { 1. To sharpen the observational skills and abilities of } \\
\text { participants. Each intervention lesson was designed to } \\
\text { assist the participants in their observational skills during } \\
\text { the art-making process. }\end{array}$ \\
\hline Post-test & $\begin{array}{l}\text { 1. To track and compare the progress of participants from } \\
\text { the pre-test to the post-test. } \\
\text { 2. To evaluate the effectiveness of the intervention lessons } \\
\text { on the observational skills and abilities of the participants. }\end{array}$ \\
\hline
\end{tabular}

Source: Mostert, W.A., 2020, 'The development of Visual Perception in Visual Art in the Primary Source: Mostert, W.A., 2020 , The development Unpublished Masters thesis, Cape Peninsula University of Technology, Cape Town.
School
- How can teachers assist in the development of visual perception in Visual Arts in the primary school?

\section{Sample}

The participants of the study were four Grade 5 classes. Two of the classes formed the test group and two formed the control group. During the study, the two test groups were subjected to eight intervention lessons to sharpen their visual perceptual skills. Both the test group and control group completed a $2 \mathrm{D}$ pre-test and a $2 \mathrm{D}$ post-test to determine the efficacy of the intervention.

\section{Data collection}

The data collected during the study was performed through four main instruments namely a 2D artwork (pre-test), eight intervention lessons, a 2D artwork (post-test), and observations in the form of field notes (for details see Table 1).

\section{Data analysis}

To answer the main research question that guided this study, the data from the pre-test, intervention lessons, and the post-test were analysed. The field notes were transcribed and converted to full text, and the visual data were studied and scrutinised to identify codes and patterns, and themes.

The textual data and visual data from the pre-test were studied and scrutinised to identify the level of perceptual and observational awareness of the test group and the control group. Once the pre-test was completed, the artworks were assessed and the results of the test and control group were compared to ascertain whether both groups' observational skills were on par with one another. After the pre-test data were studied, the field notes and visual data from the eight intervention lessons were studied and scrutinised to identify codes and patterns. The pre-test field notes and visual data were examined to identify codes and patterns. The post-test was assessed, and the results were compared between the test group and the control group.

Finally, the post-test visual and field note data were coded, and themes were identified to describe visual perception at a post-test level. Following the suggestions of Cohan, Manion and Morison (2007:477), the data were broken up into units of analysis, and codes were assigned to the data. Categories were formed by grouping the units of data into groups, patterns and themes. At the end of the analysis process, the data from the pre-test, intervention lessons, and the post-test were compared and discussed in tabular form to ascertain whether the intervention lessons yielded significant changes in the artwork created by Grade 5 learners.

\section{Ethical considerations}

Ethical clearance was obtained from the principal of the school where the research was conducted, the Department of Education and the Ethics Committee at the university. 
The researcher considered that all the participants of the four Grade 5 classes in the study had the right to anonymity and that their privacy was regarded as highly important. The nature of the perception sharpening exercises had no harmful effects on the participants of the study. All the exercises done with the test groups were done with the control groups after the research was completed (20160317-8889).

\section{Research results}

From the analysis of the research data four main themes were identified to answer the main research question, namely creativity and the U-curve, creative and visual problemsolving, intrinsic motivation, and a shift to understanding and knowledge.

\section{Creativity and the U-curve}

Creativity is a unique form of intelligence that allows learners to creatively and logically respond to a multitude of problems they may encounter during the art-making process (Sharp 2004:5). The creative attempts of middle childhood learners may be subject to a self-imposed demand to achieve realism in their artworks. As a result of their inability to draw and create from the natural world (realistic artworks), their creativity and artistic interest might take a downwards slump or also known as the U-curve slump.

Cohn (2012:178) suggested that a cause for a decline in the creativity of learners in middle childhood could be because of growing frustration and hesitation to draw or create. This frustration grows from an inability to draw from observations and mental imagery. During the pre-test of the study, it was noticed that a large group of learners were hesitant to create or draw subject matter. They grew frustrated with the drawing process and verbalised their concerns about their inability to capture realistic images of what they observed. Cohn (2012:168) postulated that to articulate what is visually perceived through drawing and art activities, it is necessary to teach learners how to organise their creative thoughts and how to apply specific skills. These skills can be seen as different modes of observation and an understanding of what is being taught. Proper observational skills and visual perceptual skills are essential to present what is perceived graphically. The challenges of the creative slump identified during the pre-test were addressed in the intervention period of the study. The learners were taught to critically and creatively reason and think about what they visually perceived, and were taught how to apply different modes of observation during the drawing process.

Alter's (2010:1) views, which is concurred by Cohan (2012), suggested that it is vital to teach young learners how to balance artistic techniques, skills, abilities, and how to make critical judgements about their own works for creative growth to take place. During the intervention period, the learners were taught to make use of their observational skills by including cognition and creative reasoning. Throughout the intervention process, the test group proved that they were able to adapt and incorporate new observational skills and abilities through visual and mental reasoning and comparison of the subject matter. Alter (2010:1) further stated that young learners will not be able to engage in creative thinking - and problem-solving if they do not see art-making as an expressive outlet because of disinterest and inability to apply skills. Drawing on the conceptual framework of Piaget's (1952) theory of constructivism and Edwards' (1999) cognitive shift model, the learners were introduced to a new way of thinking and reasoning creatively and they had to construct their own knowledge of how to observe and recreate subject matter. This was evident during the intervention period and from the results of the post-test. The post-test indicated that the learners were able to apply the skills and newly constructed knowledge through the way they presented subject matter in their artwork.

The comparison between the pre-test and the post-test suggests that the learners improved their ability to visually portray what they perceived through creative reasoning skills and creative problem-solving abilities related to the visual perception of subject matter.

\section{Creative and visual problem-solving}

According to Stavridi (2015:2278), creativity is the gateway to creative problem-solving. During art activities, learners have to rely on creative and original methods of thinking and reasoning about subject matter and how to solve problems creatively. This study aimed to enable learners to render what they visually perceive by enhancing their perceptual skills and abilities and critical reasoning skills. Chishti and Jehangir (2014:83), suggested that learning through Visual Arts can help to develop creative thinking and the attainment of important cognitive abilities such as creative visual problem-solving. During the study, and especially the intervention period, the learners had to find a way to draw and record subject matter creatively. They had to visually and mentally resolve problems related to the drawing process to complete the exercises.

Ulger (2018) cited that while solving problems during the art-making process, it is important for learners to acquire 'structural knowledge' and a deeper understanding of the characteristics of subject matter. The participants were taught to observe and analyse the structural elements of objects, such as size, shape, edges, and lines, to gain knowledge and an understanding of the object so that they could best come up with solutions of how to represent what they visually perceived graphically.

Rosier (2010:14) stated that visual memory, along with the prefrontal cortex, work together to enhance and creatively solve problems during the art-making process. If creative problemsolving is to be employed, a strong visual component (perception/observation) is needed. Visual memory is enhanced through visual imagery and an understanding of what is perceived by mentally and visually comparing differences and similarities of the subject matter. The participants were able to creatively solve problems they encountered during the 
intervention period and the post-test by relying on visual memory, observational skills, and haptic perception. Through their understanding and knowledge of the structural elements stored in their memory, they were able to resolve the issue of portraying subject matter in the absence of visual input.

Eisner (2002:26) postulated that when learners encounter problems during art-making activities, they can creatively and systematically resolve them through the process of metacognition. During this process, newly formed concepts and knowledge are linked to existing knowledge. Rosier (2010:17) stated that meta-cognition is a person's awareness of their own thoughts and what might influence their thinking. The participants were able to form links between newly formed knowledge and their understanding of observational techniques demonstrated by their ability to recall images from memory and to use tactile sensation to recreate subject matter in their artworks. Rosier (2010:17) added that through meta-cognitive thinking, learners' problem-solving strategies are further developed by their ability to strategise solutions to problems through the knowledge they previously constructed during art activities.

\section{Intrinsic motivation}

According to Jaquith (2011:15), intrinsic motivation stems from a positive and productive reaction to the task or project being undertaken. This reaction can be seen as 'interest, involvement, curiosity, satisfaction, or positive challenges'. Stanko-Kaczmarek (2012:304) stated that learners' emotions influence their motivation to complete a task. Positive emotions or feelings towards the task or project can affect the intrinsic motivation of learners.

This was evident during the post-test of the test group, where a larger number of the participants shared their surprise and disbelief at their improved ability to portray subject matter more life-like in their artwork. This positive reaction to their artwork motivated them to continue and complete their artwork without any assistance or motivation from the teacher. This is echoed by Chad-Friedman et al. (2018:2) who stated that when learners foster a positive attitude or sense of accomplishment towards their creations, they are more motivated to continue with their creative projects. In her study Stanko-Kaczmerek (2012), claimed that the opposite is true about the effect of negative emotions on the motivation of learners. When learners foster negative emotions towards the creative process of task, they may require extrinsic motivation. During the pre-test, a group of learners verbalised and expressed their frustration and unease to complete the project. The teacher had to motivate the learners to continue with the project.

According to Larson and Rusk (2011:94), intrinsic motivation during the creative process is introduced by a challenge or problem that seeks a solution. When learners are willing to solve the problem they may encounter, their intrinsic motivation takes effect. When intrinsically motivated, learners tend to retain more of the knowledge constructed through their art experiences and lessons. Through a heightened conceptual understanding of processes and techniques of observation, learners can excel in their creative endeavours (Chad-Friedman et al. 2018:1). The study aimed to empower learners with observational skills, which would assist them in continuing with their creative attempts and in reducing the frustration associated with the U-curve slump. At the end of the study, the researcher was able to deduce that a large number of test group participants experienced and maintained their intrinsic motivation throughout the creative process of the post-test. They exhibited a readiness to solve the problems they encountered during the creative process by solving visual and mentally challenging problems without any extrinsic motivation from the teacher.

As stated by Larson and Rusk (2011:93), intrinsic motivation allows the learner to mentally process information that facilitates attention and cognitive abilities to complete projects and artworks. The skills and abilities the participants attained during the intervention process were amplified through intrinsic motivation. The researcher was able to see that the participants were more engaged in the activities and procedures during the intervention period leading up to and during the post-test. Intrinsic motivation also improves attention and focus on the task and the learning process. When learners are intrinsically motivated, they can learn faster and retain newly formed knowledge for longer. The participants were able to apply new sets of knowledge and an understanding of how to render real-life subject matter through the observational skills they attained during the intervention lessons. When learners are better equipped with visual perceptual skills - and observational skills, their intrinsic motivation might sustain their creative attempts.

Through intrinsic motivation, learners are able to make use of different strategies, such as meta-cognitive strategies, to complete their tasks. These strategies include planning and integrating previously learned skills to achieve and complete the task at hand (Larson \& Rusk 2011:96). The participants were able to plan and make use of new observational skills and techniques during the post-test by building on the skills and knowledge they attained during the intervention period.

\section{A shift to understanding and knowledge}

To ascertain whether the participants were able to make a shift to a deeper understanding of various visual perceptual and observational skills, and to construct their own knowledge of how to observe and portray subject matter, the researcher referred to the conceptual framework of this study as it relates to Piaget's theory of cognitive development in visual arts education.

As described by Efland (2002:27), cognitive development and the construction of new knowledge is not a passive process, but instead, is put forth through the actions of the learner. When the learner is actively involved in the acquisition of new skills and abilities, they are actively constructing an understanding of the processes, thus leading to new 
knowledge. This view is echoed by Olusegun (2015:66), who stated that learners should be 'active agents in the process of knowledge acquisition'. During the intervention period of the study, the participants were able to display their understanding of different skills and techniques of how to observe and portray real-life subject matter in their drawings. They were actively engaged during the intervention exercises to construct an understanding of various observation techniques that they were able to employ later during the post-test.

Heard (2007:14), stated that the construction of knowledge occurs through various modes of instruction and experience of the participants. Through the participants' experience of different methods of observation and perceptual sharpening exercises, they were able to construct new knowledge of how to observe and depict subject matter in their artwork. Olusegun (2015:66) suggested that learners construct knowledge and meaning through their experiences of active techniques they are taught. The active techniques the participants were shown during the intervention period assisted them in forming an understanding of the processes involved during the thorough observation of real-life subject matter in the visual art process.

Jenson (2018:75) suggested that learners can develop holistically through the acquisition of new skills and abilities promoted through Visual Arts. Their artistic abilities are refined, and new knowledge is constructed during the process. Pritchard and Woollard (2010:45) argued that constructivist learning is associated with critical thinking, motivation, and problem-solving. The participants were able to improve their intrinsic motivation and sharpen their problem-solving skills during the study. They were able to think critically about the techniques they were taught and how to make use of them during the post-test artwork. Hansen (2000:24) reiterated the importance of intrinsic motivation during the learning process. When learners are intrinsically motivated to learn and understand, they can build on their experiences and construct new knowledge. Heard (2007:14) explained that intrinsic motivation will lead learners to make mistakes and to learn from it so that they can build a better understanding of how to employ different strategies during the creative process.

\section{Discussion}

The results of the analysis of the data indicated that the perceptual and observational training had a marked effect on the participants' ability to record what they visually perceived. They were able to engage with the subject matter through strategies and methods they obtained during the observational training.

Multi-sensory techniques proved to be an effective way of engaging most participants during the intervention exercises. Teaching learners to think and reason in non-conventional ways helped them to understand and try different methods that proved to enhance their ability to record and draw subject matter.
A deeper understanding and knowledge of children in middle childhood and factors that might influence their visual perceptual and observational abilities proved to be imperative to assist them. Another important and valuable tool in assisting the participants was the quality of meaningful instructions during the Visual Art lessons that focused on and fostered their creative and innovative skills and abilities, which was indispensable for the development of their perceptual and cognitive skills. When Visual Arts educators teach young learners new skills and techniques, the focus should not be on creating photo realistic art, but rather techniques and skills they can understand and interpret to create age appropriate art.

The factors that were identified ranged from biological maturation, lack of intrinsic motivation, untrained visual perceptual and observational skills and abilities, and lack of understanding of various techniques required during visual arts lessons and projects. Through the training and development of visual perceptual skills, their observational skills were sharpened. The improvement of their perceptual and observational skills enabled learners to overcome the factors that inhibited their observational abilities.

The results from the pre-test and post-test indicated that the visual sharpening exercises during the intervention period were able to improve the learners' abilities to portray subject matter in their artworks visually. The The CAPS (Curriculum and Assessment Policy Statement) curriculum was followed and supplemented in the form of the intervention. It was clear that there were no specific skills or techniques on how to improve visual perception present in the CAPS curriculum. If teachers want to improve their learners' visual perceptual and observational skills, they will need to supplement the CAPS curriculum.

From the data that were collected and analysed, it was clear that the visual perceptual training in the form of the intervention lessons was able to assist the learners in their Visual Art projects. The various techniques and skills covered during the intervention period enabled the learners to construct a new understanding and knowledge of how to present what they visually perceived. Through the attainment of new skills and knowledge, the learners gained more confidence in their ability to create in Visual Art. Their improved confidence sparked their intrinsic motivation and allowed them to excel in their creative attempts. The intervention lessons sharpened their visual problem-solving skills, and it was evident that they were able to visually and mentally compare differences and similarities of the subject matter they observed.

\section{Implications and recommendations}

It would be recommended that the Department of Basic Education (DBE) revise and supplement the CAPS curriculum for Visual Arts by including a visual perceptual development methodology to allow learners to fully develop the necessary skills and abilities required for keener observation during their Visual Arts projects. The CAPS curriculum should be supplemented, and more time should be allocated for the 
teaching and development of important skills and abilities. More emphasis should be given to the learning opportunities offered through meaningful and quality Visual Arts education.

The outcome and findings of this study suggest that through a focused intervention the visual perceptual skills of the participants improved while completing their Visual Art projects. They were able to construct new knowledge and strategies associated with visual perception and observation of subject matter, which they drew creatively in their artworks. Visual Art as a subject has the ability to offer learners a multitude of skills and abilities to assist their holistic development. This was evident by the cognitive and intrinsic benefits the participants experienced during the intervention period.

The study highlights some shortcomings in the visual literacy skills contained in the CAPS curriculum in Visual Arts. Educators teaching Visual Arts should be made aware of the importance of visual perceptual development and should include such strategies during art lessons. It is hoped that this research will inform policymakers and curriculum designers of the importance of including visual perceptual development in the curriculum to supplement the observational skills of learners in middle childhood.

\section{Acknowledgements Competing interests}

The author declares that he has no financial or personal relationships that may have inappropriately influenced him in writing this article.

\section{Author's contributions}

W.M is the sole author of this article.

\section{Funding information}

Publishing of this article was funded by the Department of Education, Faculty of Social Sciences of the Cape Peninsula University of Technology, Cape Town.

\section{Data availability}

Data sharing is not applicable to this article as no new data were created or analysed in this study.

\section{Disclaimer}

The views and opinions expressed in this article are those of the author and do not necessarily reflect the official policy or position of any affiliated agency of the author.

\section{References}

Alter, F., 2010, 'Using the visual arts to harness creativity', Unesco E-Journal 1(5) viewed 25 May 2018, from https://pdfs.semanticscholar.org/319a/592fc933573c 004cb987f5e3da445a11feb3.pdf.

Anttila, E., William, H., Doan J., Barrett, T., Ruthmann, A.S., Pavlou, V. et al., 2014, 'An interdisciplinary approach for understanding artworks: The role of music in visual art eEducation', International Journal of Education \& the Arts 15(11), viewed 03 March 2015, from http://www.ijea.org/v15n11/.
Bassey, M., 1999, Case study research in educational setting, Marston Book Services Limited, Oxford.

Cahen, A. \& Tacca, M.C., 2013, 'Linking perception and cognition', Frontiers in Psychology 4, 144. https://doi.org/10.3389/fpsyg.2013.00144

Carrol, K.L. \& Tucker, J.L., 2007, Better practice in visual arts education, Maryland State Department of Education, Baltimore, MD.

Chad-Friedman, E., Lee, Y., Liu, X. \& Watson, M.W., 2018, 'The effects of visual arts pedagogies on children's intrinsic motivation, creativity, artistic skill, and realistic drawing ability', Journal of Creative Behaviour 53(4), 482-495. https://doi. org/10.1002/jocb. 228

Chishti, R. \& Jehangir, F., 2014, 'Positive effects of elementary visual art on problem solving ability in later years of life', FWU Journal of Social Sciences 8(1), viewed 18 November 2018, from https://pdfs.semanticscholar.org/6165/07534845b63f9ac November 2018, from https://pd
336e72a39a66ad4c2317d.pdf.

Cohan, L., Manion, L. \& Morrison, K., 2007, Research methods in education, Routledge, New York, NY.

Cohn, N., 2012, 'Explaining "I can't draw": Parallels between the structure and development of language and drawing', Human Development 55, 167-192. https://doi.org/10.1159/000341842

Cook, J.L. \& Cook, G., 2005, Child development, Pearson education, London.

Creswell, J.W., 2007, Qualitative inquiry and research design: Choosing among five approaches, Sage, Los Angeles, CA.

Deveau, J. \& Seitz, A.R., 2014, 'Applying perceptual learning to achieve practical changes in vision', Frontiers in Psychology 5, 1166. https://doi.org/10.3389/ fpsyg.2014.01166

Edwards, B., 1999, The new drawing on the right side of the brain, Penguin Putnam Inc., New York, NY.

Efland, A.D., 2002, Art and cognition, Teachers College Press, New York, NY.

Eisner, E.W., 2002, The art and the creation of mind, R.R. Donnelley \& Sons, Harrisonburg, VA.

Ghazi, S.R. \& Ulah, K., 2015, 'Concrete operational stage of Piaget's cognitive development theory: An implication in learning general science', Gomal University Journal of Research 31(1), 78-89.

Haanstra, F., 1996, 'Effects of art education on visual-spatial ability and aesthetic perception: A quantitative review', Studies in Art Education 37(4), 197-209. https://doi.org/10.2307/1320854

Hansen, R.E., 2000, 'The role of experience in learning: Giving meaning and authenticity to the learning process in schools', Journal of Technology Education 11(2). https://doi.org/10.21061/jte.v11i2.a.2

Heard, J.M., 2007, 'My experiences incorporating constructivist teaching strategies with an art education classroom', Unpublished Masters thesis, Georgia State with an art education
University, Atlanta, GA.

Jaquith, D.B., 2011, 'Creativity? Intrinsic motivation and autonomy in children's artmaking', Art Education 64(1), 14-19. https://doi.org/10.1080/00043125.2011.11519106

Jenson, K., 2018, 'Early childhood: Learning through visual arts', He Kapu 5(3), viewed 28 May 2019, from https://www.hekupu.ac.nz/article/early-childhood-learningthrough-visual-art.

Kiese-Himmel, C., Witte, C., Islam, S. \& Von Steinbuchel, N., 2015, 'Art-based education in pre-school children - An exploratory study', International Journal of Education and Social Sciences 2(4), viewed 30 March 2016, from www.ijessnet.com.

Larson, R.W. \& Rusk, N., 2011, 'Intrinsic development and positive development', in J. Lerner, R. Lerner \& J. Benson (eds.), Advances in child development and behaviour, pp. 89-130, Academic Press, Burlington, VT.

Letsiou, M., 2014, 'Art intervention and social reconstruction in education', Art Education and Culture 3(2), viewed 16 June 2017, from http://revistaselectronicas. ujaen.es/index.php/RTC/article/view/3092.

Lowenfeld, V. \& Brittain, W.L., 1975, Creative and Mental Growth, 6th edn., Macmillian, New York.

Machera, R.P., 2017, 'Teaching intervention strategies that enhance learning in higher education', Universal Journal of Educational Research 5(5), 733-743. https://doi. org/10.13189/ujer.2017.050505

Mostert, W.A., 2020, 'The development of Visual Perception in Visual Art in the Primary School', Unpublished Masters thesis, Cape Peninsula University of Technology, Cape Town.

Olusegun, S., 2015, 'Constructivism learning theory: A paradigm for teaching and learning', IOSR Journal of Research and Methods in Education 5(6), viewed 15 March 2019, from http://www.doi:10.9790/7388-05616670.

Orde, B.J., 1997, 'Drawing as visual - Perceptual and spatial ability training', in presentations at the 1997 National Convention of the Association for Educational Communications, Albuquerque, February 14-18, 1997, The Institute, Mexico, pp. 271-276.

Payne, R., 2012, Seen, unseen or overlooked? How can visual perception develop through a multimodal enquiry?, Blackwell Publishing Ltd., Oxford.

Piaget, J., 1952, The origins of intelligence in children, Norton \& Co., New York.

Polat, U., 2009, 'Making perceptual learning practical to improve visual functions', Vision Research 49(21), 2566-2573. https://doi.org/10.1016/j.visres.2009.06.005

Pritchard, A. \& Woollard, J., 2010, Psychology for the classroom: Constructivism and social learning, Routledge, London.

Pujara, S., Atkins, M. \& McMahon, S., 2014, Art-based projects for children and young people, Metropolitan University, London.

Rosier, J.T., 2010, 'Art and memory: An examination of the learning benefits of visual-art exposure', Unpublished Masters thesis, Georgia Southern University, Atlanta, GA. 
Sharp, C., 2004, 'Developing young children's creativity: What can we learn from research?', Readership, Primary 8, 32, viewed 06 June 2015, from https://www. nfer.ac.uk/publications/44420/44420.pdf.

Stanko-Kaczmarek, M., 2012, 'The effect of intrinsic motivation on the affect and evaluation of the creative process among fine arts students', Creativity Research Journal 24(4), 304-310. https://doi.org/10.1080/10400419.2012.730003

Stavridi, S., 2015, 'The role of interactive visual art learning in development of young children's creativity', Creative Education 6(21), 2274-2282. https://doi.org/10. 4236/ce.2015.621235
Ulger, K., 2018, 'Effects of problem-based learning on the creative thinking and critical thinking disposition of students in visual arts education', Interdisciplinary Journal of Problem-Based Learning 12(1). https://doi.org/10.7771/15415015.1649

Wachowiak, F. \& Clements, R.D., 2010, Emphasis art: A qualitative program for elementary and middle schools, Allyn \& Bacon, Boston, MA.

Zimmerman, E., 2009, 'Reconceptualizing the role of creativity in art education theory and practice', Studies in Art Education 50(4), 382-399. https://doi.org/10.1080/0 0393541.2009.11518783 